taken a stage further than many similar methods by the construction of a pilot-plant scale process and has gone some way to dispel the criticisms of the Spinks report $^{8}$ which concluded that Britain was again failing to take full commercial and industrial advantage of new technologies to which she has contributed so successfully at the primary research level. Not only has a system been reported which has scientific value, but by careful investigation, the industrial production of a naturally occurring disaccharide with great potential as a non-carciogenic bulking agent for foodstuffs and pharmaceuticals can be realised with very few of the problems of purification and contamination associated with industrial enzymic methods. It is hoped that this paper will stimulate further investigations into the industrial applications of immobilized cell technology. $\square$

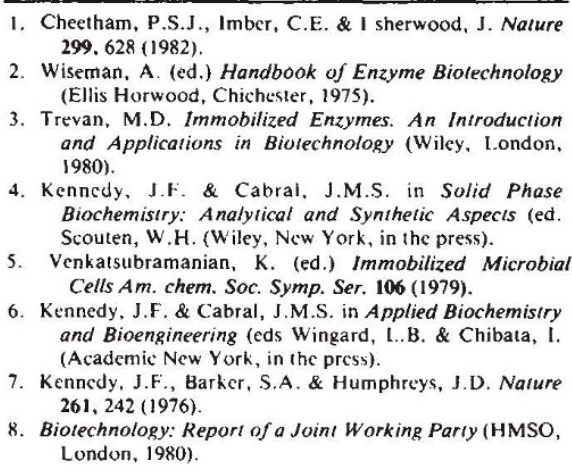
299. 628 (1982)

2. Wiseman, A. (ed.) Handbook of Enzyme Biolechnology (Ellis Horwood, Chichester, 1975).

3. Trevan, M.D. Immobilized Enzymes. An Introduction and Applications in Biolechnology (Wiley, London,

4. Kennedy, JF \& Cabral JM.S in Solid Phase Biochemistry: Analytical and Synthetic Aspects (ed. Scouten, W.H. (Wiley, New York, in the press).

Scouten, W.H. (Wiley, New York, in the press).
Venkatsubramanian, K. (ed.) Immobilized Microbia Cells Am. chem. Soc. Symp. Ser. 106 (1979).

6. Kennedy, J.F. \& Cabral, J.M.S. in Applied Biochemistry and Bioengineering (eds Wingard, L..B. \& Chibata, I. (Academic New York, in the press).

Kennedy, J.F., Barker, S.A. \& Humphreys, J.D. Nature 261, 242 (1976).

8. Biotechnology: Report of a Joint Working Party (HMSO, London, 1980).

\title{
Immunoregulation by gamma-interferon?
}

\section{from Teresa Basham and Thomas C. Merigan}

THE potential of interferons as immunoregulatory as well as antiviral and antitumour agents is currently of great interest. With the advent of genetic engineering, pure preparations of biosynthetic interferons are now available for a precise examination of both their effectiveness in clinical trials and their mechanism of action. In this issue of Nature (p.833), David Wallach, Marc Fellous and Michel Revel describe a difference between pure recombinant gamma-interferon (IFN- $\gamma$ ) and the other interferons in the induction of the major histocompatibility antigens HLA-A,B,C which they suggest may be related to interferon's immunoregulatory function.

IFN- $\gamma$, a lymphokine derived from $\mathrm{T}$ lymphocytes, is one of three different types of interferons, each distinguished by protein sequence, antigenicity and physiochemical properties. The other two types are alpha-interferon (IFN- $\alpha$ ) from leukocytes and beta-interferon (IFN- $\beta$ ) from fibroblasts. IFN- $\gamma$ is closely linked to the immune response and can be induced by a wide variety of substances, including mitogens, bacterial and viral antigens, and tumour cells, while IFN- $\alpha$ and IFN- $\beta$ are induced predominantly by viruses. In addition to antiviral activity, all three have been shown to have cytostatic and immunoregulatory functions, to modify cell structure, membranes and differentiation, and to induce the synthesis of several new proteins'. The exact mechanism by which the different interferons exert these various activities is not

Teresa Basham and Thomas C. Merigan are in the Division of Infectious Diseases, Department of Medicine, Stanford University School of Medicine, Stanford, California 94305. yet clear, and recent interest has focused on this problem.

Earlier work had shown that in the murine system, impure IFN- $\gamma$ preparations increased the expression of the histocompatibility antigens $(\mathrm{H}-2)$ at doses 100 10,000 times lower than those required using IFN- $\alpha$ (ref. 2), and that IFN- $\gamma$ is 250 times more potent in immune cell regulation than the other interferons ${ }^{3,4}$. But these experiments used only partially purified interferons so it was possible the preparations contained other lymphokines. Using purified recombinant IFN- $\gamma$ Wallach and his colleagues have now confirmed increased potency of IFN- $\gamma$ in inducing HLA expression. Furthermore, they describe a differential response between the dose of recombinant IFN- $\gamma$ required for the induction of HLA antigens and the enzyme $\left(2^{\prime}-5^{\prime}\right)$ oligoadenylate synthetase, which inhibits protein synthesis and is related to the antiviral activity of interferon. In contrast, IFN- $\alpha$ and IFN- $\beta$ induced both of these cellular proteins at the same concentration. Thus Wallach and his associates suggest that the induction of the HLA antigens is not related to the antiviral activity of IFN- $\gamma$ and that IFN- $\gamma$ is the most important interferon in immune regulation.

Three recent papers showed that in a variety of cell types, interferon's effect on HLA expression occurs though a corresponding increase in the specific biosynthesis of these antigens ${ }^{5.6}$ and the mRNA pool for the HLA sequences ${ }^{6.7}$. The optimum dose of interferon required for maximum HLA synthesis and expression varied from one cell line to another. For example, Basham et al. found that as low as $50 \mathrm{U} \mathrm{ml}^{-1}$ of IFN- $\alpha$ were sufficient to induce maximum HLA biosynthesis and expression in human melanoma cell lines sensitive to the antiviral activity of IFN- $\alpha$ but resistant to its antiproliferative action, whereas Burrone et al. used 2,000 U ml-1 of IFN- $\alpha$ to induce a similar response in a $\mathrm{T}$-cell line (Molt 4). Therefore, although it is intriguing that IFN- $\gamma$ can induce HLA expression at a much lower concentration than that required for induction of $\left(2^{\prime}-5^{\prime}\right)$ oligoadenylate synthetase and antiviral activity, it is possible that any or all of these cell surface-related effects vary from one cell line to another, and many well characterized cell lines should be tested before a conclusion is drawn.

The function of the interferon-induced increases in HLA antigens is at present purely speculative but may well be related to cell-cell recognition. The most obvious role is in potentiating the cytotoxic T-cell response of a virally infected host for the elimination of HLA-matched infected cells. Wallach and co-workers suggest that the increase in HLA expression may also protect uninfected host cells from lysis by natural killer cells.

A claim for a role for IFN- $y$, rather than the other interferons, in immune regulation would be much stronger if IFN$\gamma$ were shown to have a differential effect on the expression of the immune response antigens that are critical in antigen presentation by macrophages to lymphocyte subpopulations. Wallach et al. observed no increase in HLA-DR in a human B-cell line (Ramos). In contrast, using different cell types and impure IFN$\gamma$, Sonnenfeld and colleagues ${ }^{2}$ and, more recently, others ${ }^{8}$ found an increase in the human HLA-DR analogue, Ia, on murine cell surfaces. It is possible that Wallach $e t$ al. missed this effect of IFN-y on HLA-DR because B-lymphoblastoid cell lines have a higher HLA-DR concentration on their surface initially.

More work on interferon's effects on antigen expression and regulation of the immune response will undoubtedly be done and should eventually clarify their contribution to the biological role of the interferons.

\footnotetext{
Vilcek, J., Gresser, I. \& Mcrigan, T.C. (cds) Regulatory Functions of Interferon (New York Academy of Sciences, Ncw York, 1980).

2. Sonnenfeld, G., Meruelo, D., MeDevitt, H.O. \& Merigan. T.C. Cell. Immun. 57, 427 (1981).

3. Sonnenfeld, G., Mandel, A.D. \& Merigan, T.C. Cell. Immun. 34, 193 (1977):

4. Virclizier, J.L., Chan, E.L.. \& Allison, A.C. Clin. exp. Immun. 30. 299 (1977)

Basham, T.Y., Bourgeade, M.F., Creasey, A.A. \& Metigan, T.C. Proc. natn. Acad. Sci. U.S.A. 79, 3265 (1982).

Burronc, O.R. \& Milsicin, C. EMBO J. 1/3, 345 (1982)

Fillous, M. el al. Proc. natn. Acad. Sci. U.S.A. 79, 3082 (1982)

Steeg, P.S., Moore, R.N., Johnson, H.M. \& Oppenheim,
} J.J. J. exp. Med. (in the press).

\section{ADDENDUM}

The article 'Glomar Challenger at the Cretaceous-Tertiary boundary' was authored not just by three, but by all 18 of the DSDP leg 86 scientific staff. 